\title{
Experimental investigations for dimensional accuracy and surface finish of polyurethane prototypes fabricated by indirect rapid tooling: a case study
}

\author{
Jaspreet Singh $^{1,2} \cdot$ Rupinder Singh $^{3} \cdot$ Harwinder Singh ${ }^{4}$
}

Received: 3 July 2016/ Accepted: 25 April 2017/Published online: 29 April 2017

(C) Springer International Publishing Switzerland 2017

\begin{abstract}
In this research work, an effort has been made to study the influence of selected input parameters on the dimensional accuracy (linear as well as radial) and surface finish of polyurethane prototypes fabricated by vacuum casting (VC) process as a case study. The master pattern required for making a silicone mould has been fabricated by fused deposition modelling and its surface finish has been enhanced by chemical vapour smoothing process. Maximum shrinkage of 2.29 and $4.77 \%$ has been observed in the selected linear and radial dimension, respectively, after the VC process. Optimal parameter settings that were different for both the dimensions as well as surface finish have been obtained using Taguchi's L18 orthogonal array. Finally, parameter setting that simultaneously minimizes the dimensional deviation and surface roughness has been found out using response optimization module of Minitab 17 software and the results obtained have been verified by performing the confirmation experiments. The tolerance grades for the selected dimension of the prototypes were found to be acceptable as per the ISO standard UNI EN 20286-I (1995) and DIN16901 for plastic materials. In addition, the $C_{\mathrm{pk}}$ value greater than 1.3 indicated that the proposed process is highly capable. The surface finish and dimensional accuracy of prototypes are at par with the
\end{abstract}

Rupinder Singh

rupindersingh78@yahoo.com

1 I.K Gujral Punjab Technical University, Kapurthala 144601, India

2 Lovely Professional University, Phagwara 144411, India

3 Production Engineering Department, GNDEC, Ludhiana 141006, India

4 Mechanical Engineering Department, GNDEC, Ludhiana 141006, India traditional moulding patterns, and hence, they can be used as end-products or plastic-based master patterns for investment casting applications.

Keywords Dimensional accuracy · Surface finish · Polyurethane · Vacuum casting · Fused deposition modelling · Chemical vapour smoothing · Taguchi's L18 orthogonal array · UNI EN 20286-I (1995) · DIN16901

\section{Introduction}

In today's scenario, market requires faster product development along with low cost, high quality, and better efficiency. Rapid prototyping (RP) is one of the additive manufacturing (AM) processes that reduce the product development cycle time and cost of the product [1]. RP utilizes computer-aided design (CAD)-based manufacturing process to construct prototypes that can be used directly as finished products [2,3]. RP consists of a variety of manufacturing techniques that build the 3D component by adding material layer by layer $[4,5]$. Currently, RP technologies are not preferred for small-to-medium quantity production due to the high cost involved and also have limited range in terms of material selection [6]. This requires the need of developing rapid tooling (RT), which is an extension of RP. It is the technology that utilizes the $\mathrm{RP}$ and applies them to the manufacturing of various tools $[4,5,7]$. In general, RP cuts down product development time and RT cuts down the production time [8]. Further, RT can be classified as either direct or indirect. Direct tooling techniques are those which utilize AM techniques for the fabrication of the mould and then these moulds are used for producing prototypes of various materials. Direct metal laser sintering (DMLS), ProMetal, LENS, and Direct 
AIM are some AM processes that have been used successfully for direct fabrication of moulds for producing wax patterns [9]. Indirect tooling involves fabrication of mould from an AM master pattern, which is then used to manufacture multiple prototypes. Silicone rubber tooling, epoxy resin tooling, and spray metal tooling are some common examples of indirect RT. Silicone moulding (SM) is an established prototyping technique widely used in industry to produce wax patterns $[10,11]$ and various types of plastic parts due to high chemical resistance of silicone rubber and low interfacial energy of its surface. SM is a characterized by the use of a vacuum during the process of mould fabrication and the casting of plastic parts [12]. In SM process, initially, a master pattern using any of the RP technology has been fabricated. After that a release agent is applied and then liquid silicone along with some hardener is cast around the RP pattern inside a mould box. Then, the mould is left around $12-18 \mathrm{~h}$ for curing. After that, the block is cut along the parting line and the pattern is removed. Runner and gating system are provided for filling of the cavity created by the master pattern. After this, the mould was re-assembled and suitable material such as wax, $\mathrm{PU}$, plastic, etc. is poured into it to produce multiple components.

Cheah et al. [13] highlighted an indirect approach for producing wax patterns via silicone rubber moulding from RP-based master pattern to reduce the costs associated with small-quantity production during the investment casting process. Dinesh and Ravi [14] discussed the number of direct routes using RP processes (FDM, LOM, SLA, SLS, etc.) as well as indirect routes (RP coupled with secondary or soft-tooling processes like RTV vacuum casting) for rapid fabrication of tooling for sand and investment casting (IC) processes. Rahmati et al. [15] investigated the dimensional accuracy of wax patterns created by room temperature vulcanized (RTV) silicone rubber moulding and concluded that vacuum pressure and its interaction with wax temperature are the most significant factors that affect the accuracy. Yarlagadda et al. [16] compared the dimensional accuracy of wax patterns produced by hard (PU mould) and soft-tooling (RTV mould) and concluded that PU mould produces more accurate patterns than the silicone mould. In addition, low pressure with higher temperature is desirable to produce accurate patterns with PU mould, whereas for the silicone mould, only the injection temperature has an effect on the dimensions of the wax patterns. Zamani et al. [17] compared the dimensional accuracy of wax pattern of gas turbine blade produced by epoxy moulds and silicone rubber moulds and concluded that epoxy mould can produce more accurate models than the silicone rubber mould. Thian et al. [18] employed vacuum casting method to produce micromoulds and microgears using silicone rubber mould and investigated that the deviation between the master pattern and its ten specimens was very small and the proposed method is highly capable of consistently producing micro parts that are dimensionally accurate with respect to the master pattern. Singh and Singh [19] made investigations to develop macro-model of silicon moulding process for the fabrication of plastic components with regard to dimensional accuracy and concluded that the tolerance grades for plastic components prepared with SM are consistent with the permissible range of tolerance grades as per ISO standard UNI EN 20286-I (1995) and DIN16901. Furthermore, Singh and Singh [20] fabricated the plastic component using SM process and highlighted the process capability of SM in terms of dimensional accuracy. Kai et al. [21] compared three techniques of producing PU parts and concluded that rapid pattern approach is the fastest and most flexible one to use. In addition, it has been suggested by the researchers that the dimensional accuracy of the traditional IC process for complex and intricate shapes can be improved by replacing the conventional wax-based pattern with the modern plastic-based patterns [22]. From the reported literature, it has been observed that lot of research work has been performed to improve the dimensional accuracy of wax patterns by optimizing the input parameters of SM process. But hitherto, very little work has been reported regarding the influence of VC process parameters on the dimensional accuracy and surface finish of PU replicas. Therefore, the author tried to explore the above gaps in this research work. The main objective of this research work is to access the repeatability of the VC process to fabricate the selected component with regard to dimensional accuracy, so that they can be utilized as a sacrificial pattern in IC process for the production of specialized or tailor made products in small-to-medium quantity.

\section{Methodology and experimentation}

In this work, a component of biomedical application (hip joint) as shown in Fig. 1 has been selected as the benchmark. The hip joint is basically a ball-and-socket joint. The socket is made of bone and cartilage, and the ball is the head of the thigh bone (femoral head). During the hip replacement surgery, the damaged hip joint is replaced with metal, plastic, or ceramic components. In general, the ball (femoral head) is removed and replaced with new and durable artificial synthetic part. The CAD model of the component has been made using the Solidworks software and then converted into STL file. The 3D physical model of acrylonitrile butadiene styrene (ABS) material has been built from the STL file using fused deposition modelling 


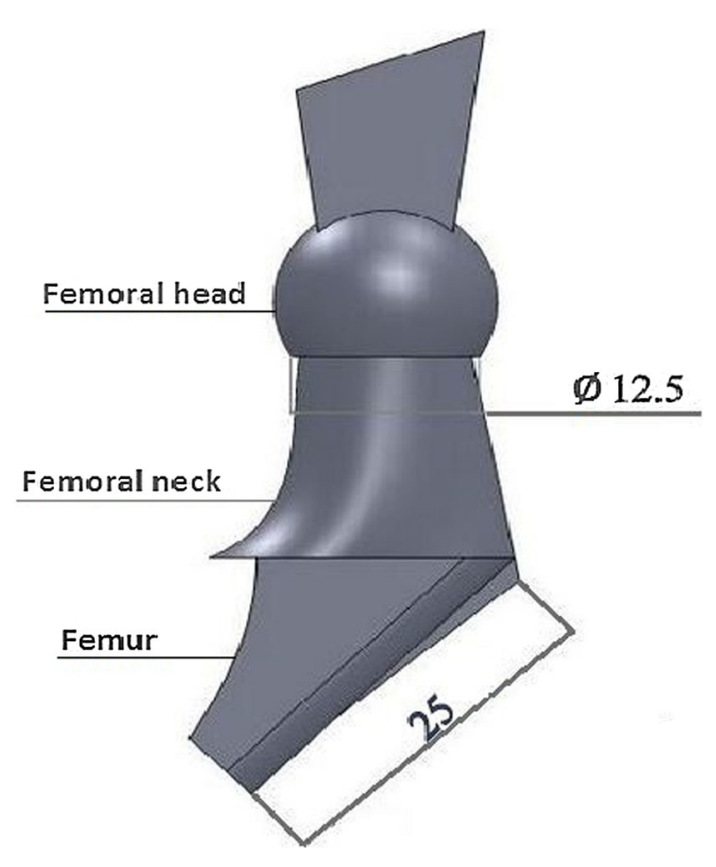

Fig. 1 Benchmark component

(FDM) technique of RP at $90^{\circ}$ of orientation angle with high part interior style. These particular levels were selected, because dimensional deviation and surface roughness $\left(R_{\mathrm{a}}\right.$ value) of master pattern were minimum at these parametric settings. Four such models at the same FDM parameters have been fabricated to create multiple cavities in silicone mould. Although, FDM process has been implemented successfully to reduce the product build time and cost, but the surface quality and dimensional accuracy of the FDM prototypes suffer badly even for basic part geometries [23]. However, some of the researchers highlighted that chemical vapour smoothing (CVS) technique drastically improves the surface finish of FDM fabricated $A B S$ replicas with minimal variation in part dimensions [24-26]. Therefore, to improve the surface finish, the ABS models were exposed to chemical vapour smoothing (CVS) process. In CVS process, the chemical vapours generally of acetone enhance the surface finish of the ABS replicas by softening the external layer as the acetone breaks the secondary bonds between the ABS polymer chains. This allows the chains to slide past each another and streams to more stable positions. Based on the literature review and pilot experimentation, five number of cycles with cycle time of $6 \mathrm{~s}$ in smoothing process has been applied to the FDM fabricated ABS master pattern to enhance the surface finish. Surface finish in the range of $(0.144-0.519 \mu \mathrm{m})$ has been achieved after the CVS process. In addition, it has been observed that CVS process slightly reduces the dimensions of the prototypes due to reflow of the material. The various parameters and their
Table 1 Parameters taken for the fabrication of master pattern

\begin{tabular}{ll}
\hline Parameter & Level \\
\hline Orientation & $90^{\circ}$ \\
Part density & High \\
No of cycles & 5 \\
Cycle time & 6 \\
\hline
\end{tabular}

levels taken to fabricate the master pattern have been shown in Table 1. The value of two critical dimensions after FDM and CVS process has been shown in Table 2.

For making silicone mould having multiple cavities, gating system such as runners, risers, etc., are attached to the fabricated master models and then put in a frame. After that silicone rubber mixture consisting of VTV-750 silicone rubber and CAT 740 catalyst as hardener in a ratio of 10:1 has been prepared, degassed by vacuum casting machine for $15 \mathrm{~min}$, and then poured into the frame. The various steps involved in making the silicone mould have been shown in Fig. 2, and after making the mould, it is ready for vacuum casting (VC). The dimensional accuracy (with deviation of around 2-3\%) and surface roughness (average $R_{\mathrm{a}}$ value $=0.340$ ) of the mould cavity have been observed before the pouring of PU resins and found to be within the acceptable range as per commercial practises. In this study, two commercially available PU resins namely Renishaw 6130 and Axson PX223 had been used for making the prototypes. Each PU consists of two resins: part A (a polymeric polyol with hydroxyl group that acts as hardener) and part B (a di-isocyanate compound that acts as softener). Tables 3 and 4 indicated the various properties of Renishaw 6130 resin and Axson PX223 resin.

In $\mathrm{VC}$, initially, the mould is placed in an oven at a specified temperature to stabilize its temperature. After that the mould has been placed in VC machine along with PU resins (part A and part B) in separate containers. Resins after degassing of $10 \mathrm{~min}$ are mixed and then poured into the mould. After pouring, the mould is again kept at some specified temperature and for a specified time to ensure that resins completely fill the cavity. The replicas fabricated by VC process have been shown in Fig. 3. The influencing parameters, their levels, and interaction between parameters have been decided on the basis of pilot experimentation. Based on the results, the effect of three input parameters such as hardener percentage, curing temperature, and curing time and the interaction between PU material and hardener percentage had been studied on the dimensional accuracy (linear as well as radial) and surface finish of PU prototypes. The levels selected for the input parameters have been shown in Table 5. The dimensional deviation of two critical dimensions, as shown in Fig. 1, has been measured by coordinate measuring machine (CMM). The average deviation in selected dimensions of 
Table 2 Two critical dimensions after FDM and CVS process

Fig. 2 Various steps involved in silicone moulding process

\begin{tabular}{llll}
\hline S. No & $\begin{array}{l}\text { Drawing dimension } \\
(\mathrm{mm})\end{array}$ & $\begin{array}{l}\text { Dimension after FDM } \\
(\mathrm{mm})\end{array}$ & $\begin{array}{l}\text { Dimension after CVS } \\
(\mathrm{mm})\end{array}$ \\
\hline 1 & 25 & 25.094 & 25.042 \\
2 & 12.5 & 12.402 & 12.356 \\
\hline
\end{tabular}
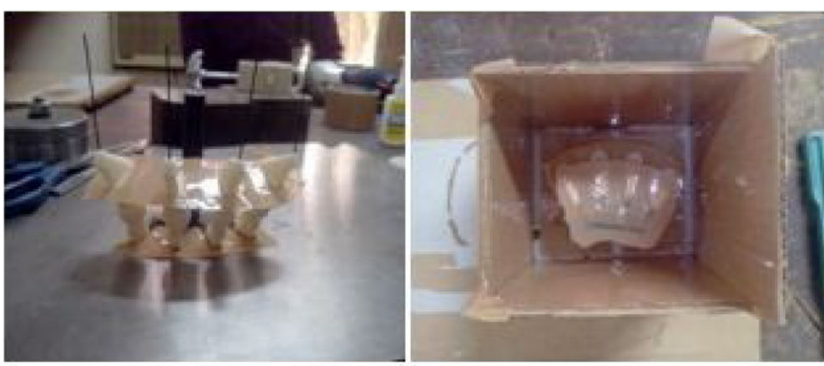

Gating attached to patterns

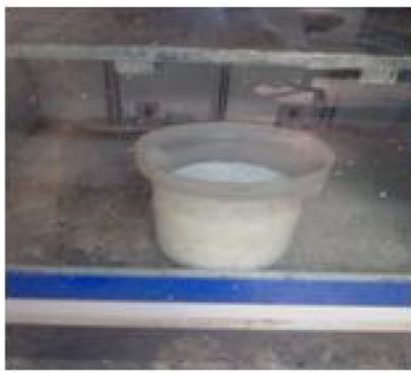

Degassing process

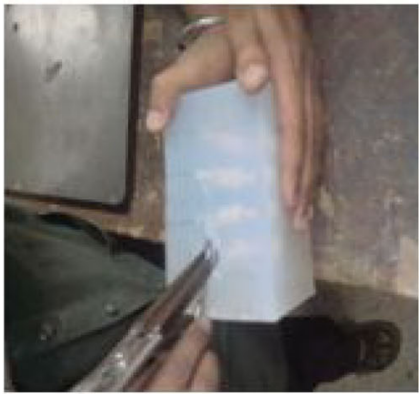

Cutting of mould assembly put in a frame

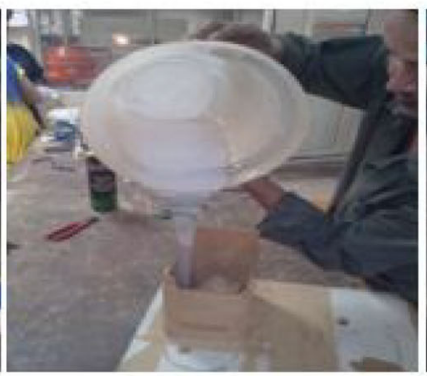

pouring of mixture in frame

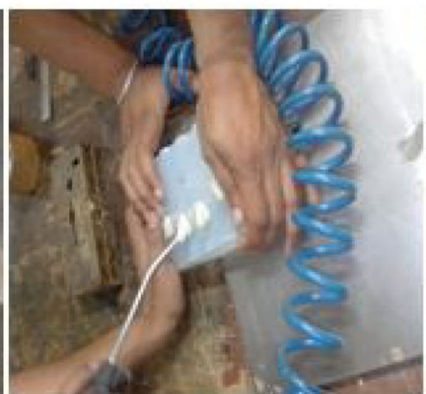

removal of pattern

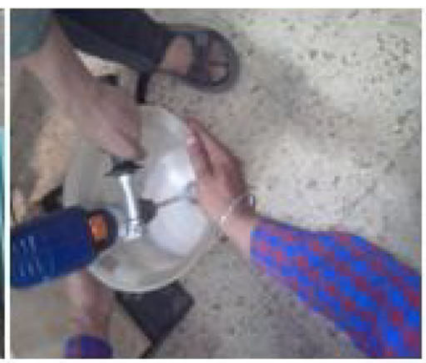

mixing of rubber and hardener

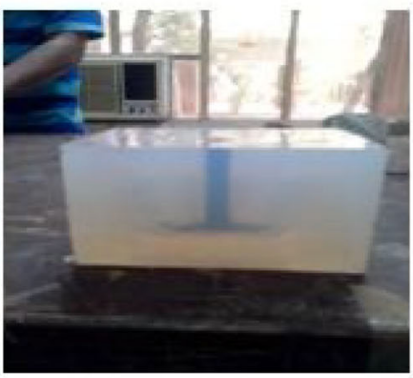

cured mould

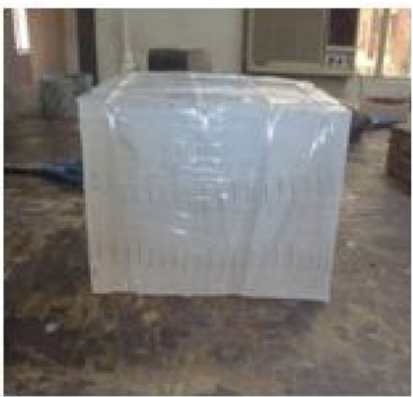

mould ready for casting

Table 3 Properties of resin 6130

\begin{tabular}{llll}
\hline & Resin 6130 A & Resin 6130 B & Mixture \\
\hline Material & Polyol & Isocyanate & \\
Appearance & Colorless transparent liquid & Colorless transparent liquid & White/translucent \\
Density @ 25 ${ }^{\circ} \mathrm{C}$ & $0.99 \mathrm{~g} / \mathrm{cm}^{3}$ & $1.14 \mathrm{~g} / \mathrm{cm}^{3}$ & $1.08 \mathrm{~g} / \mathrm{cm}^{3}$ \\
Viscosity @ 25 ${ }^{\circ} \mathrm{C}$ & $600 \mathrm{cPs}$ & $40 \mathrm{cPs}$ & $420 \mathrm{cPs}$ \\
Pot life @ 25 ${ }^{\circ} \mathrm{C}$ & & & $6 \mathrm{~min}$ \\
De-mould time at $65{ }^{\circ} \mathrm{C}$ & & & $50-80 \mathrm{~min}$ \\
\hline
\end{tabular}

prototypes after $\mathrm{VC}$ has been obtained by comparing with the dimensions of the master pattern fabricated by combined process of FDM and CVS. The surface roughness $\left(R_{\mathrm{a}}\right.$ value) of the specimens has been measured at femur (see Fig. 1) by Mitutoyo SJ-210 roughness tester at $0.5 \mathrm{~mm} / \mathrm{s}$ stylus speed, cut-off length at $0.25 \mathrm{~mm}$, and $X$ at 5 . 
Table 4 Properties of resin PX223

\begin{tabular}{llll}
\hline & Resin PX223 A & Resin PX223 B & Mixture \\
\hline Material & Isocyanate & Polyol & \\
Appearance & Colorless & Black & Black \\
Density @ 25 ${ }^{\circ} \mathrm{C}$ & $1.17 \mathrm{~g} / \mathrm{cm}^{3}$ & $1.12 \mathrm{~g} / \mathrm{cm}^{3}$ & $1.14 \mathrm{~g} / \mathrm{cm}^{3}$ \\
Viscosity @ 25 ${ }^{\circ} \mathrm{C}$ & $1100 \mathrm{cPs}$ & $300 \mathrm{cPs}$ & $850 \mathrm{cPs}$ \\
Pot life @ 25 ${ }^{\circ} \mathrm{C}$ & & & $6-7 \mathrm{~min}$ \\
De-mould time at $65{ }^{\circ} \mathrm{C}$ & & & $45-70 \mathrm{~min}$ \\
\hline
\end{tabular}

selected dimensions after the VC process in all the experiments. However, the shrinkage for PX223 is less as compared to $6130 \mathrm{PU}$ material as observed from its lower average dimensional deviation (refer Table 6). The maximum percentage of linear and radial deviation is 2.29 and $4.77 \%$, respectively, in experiment 14 . The value of surface roughness $\left(R_{\mathrm{a}}\right)$ in the range of $0.3 \mu \mathrm{m}$ to $1.7 \mu \mathrm{m}$ (as seen from Table 6) for the selected materials indicates excellent surface quality. Since the objective is to achieve both the deviation and surface roughness to be minimum, so signalto-noise $(S / N)$ ratio based on 'lower is better' has been calculated using Eq. (1) for all the three responses and shown in Table 7:

$S / N=-10 \log \left[\frac{1}{r} \sum_{i=1}^{r} Y_{i}^{2}\right]$,

\begin{tabular}{llrll}
\hline Parameters & Symbol & \multicolumn{2}{c}{ Levels } & \\
\cline { 3 - 5 } & & \multicolumn{1}{l}{1} & 2 & 3 \\
\hline PU material & A & 6130 & PX223 & - \\
Hardener \% & B & 90 & 95 & 100 \\
Curing temperature & C & 70 & 80 & 90 \\
Curing time & D & 45 & 55 & 65 \\
\hline
\end{tabular}

Taguchi's orthogonal array has been used to plan and analyze the experiments as well as to determine the optimum conditions. In this work, the total number of degrees of freedom for the selected four parameters along with the selected interaction $(A \times B)$ is 9; accordingly, the most suitable orthogonal array with a mixture of two-level and three-level variables was determined as L18 with $17 \mathrm{df}$. Since the experimental design requires only 9 degrees of freedom (DOF), the remaining DOF have been used to measure the experimental error.

\section{Results and discussion}

L18 orthogonal array along with data collected as output has been shown in Table 6 . In this research work, dimensional deviation $(\Delta d)$ and surface roughness $\left(R_{\mathrm{a}}\right)$ have been taken to represent the dimensional accuracy and surface finish, respectively. Shrinkage has been observed in the where $Y_{i}$ is the observed value of the response characteristic and $r$ number of repetitions.

For analyzing the results, analysis of variance (ANOVA) has been performed on calculated $S / N$ ratios. It helps in predicting the significance of each input parameter, which, in turn, identifies the most influencing parameter and the percentage contribution of each parameter on the desired response. Higher the percentage contribution, the more will be the effect of the input factor on the output. By controlling the factors with high contribution, the total variation can be reduced leading to improvement of process performance. 'Minitab 17' software has been used for the analysis of data obtained. The ANOVA results for the three responses have been shown in Tables 8, 9, and 10, respectively. The $P$ value less than 0.05 (i.e., $\alpha=0.05$, or 95\% CI) in Tables 8, 9, and 10 indicates that the model terms are significant. Therefore, for linear deviation, $A$ and $D$ are the significant model terms. Similarly, for radial deviation $A, B, D$, and the interaction between $A \& B$ and for surface roughness, $A, B$, and $C$ are significant model terms. Larger $F$ value for any factor indicates that variation in this factor causes large variation in performance characteristics.

Figure 4 shows the main effect plot for mean $S / N$ ratio of various factors for the average linear deviation (LD). It has been observed that LD is less for PX223 PU material as 
Table 6 L18 orthogonal array with collected data

\begin{tabular}{|c|c|c|c|c|c|c|c|}
\hline $\begin{array}{l}\text { S. } \\
\text { No. }\end{array}$ & $\begin{array}{l}\mathrm{PU} \\
\text { material }\end{array}$ & $\begin{array}{l}\text { Hardener } \\
\%\end{array}$ & $\begin{array}{l}\text { Curing } \\
\text { temperature } \\
\left({ }^{\circ} \mathrm{C}\right)\end{array}$ & $\begin{array}{l}\text { Curing } \\
\text { time } \\
(\min )\end{array}$ & $\begin{array}{l}\text { Average linear } \\
\text { deviation } \\
(\mathrm{mm})\end{array}$ & $\begin{array}{l}\text { Average radial } \\
\text { deviation } \\
(\mathrm{mm})\end{array}$ & $\begin{array}{l}\text { Average surface roughness, } \\
R_{\mathrm{a}} \\
(\mu \mathrm{m})\end{array}$ \\
\hline 1 & PX223 & 90 & 70 & 65 & 0.224 & 0.412 & 0.547 \\
\hline 2 & 6130 & 95 & 90 & 65 & 0.481 & 0.484 & 1.069 \\
\hline 3 & 6130 & 90 & 80 & 55 & 0.455 & 0.528 & 1.213 \\
\hline 4 & PX223 & 95 & 90 & 45 & 0.091 & 0.385 & 0.452 \\
\hline 5 & PX223 & 100 & 90 & 55 & 0.196 & 0.357 & 0.471 \\
\hline 6 & PX223 & 100 & 70 & 65 & 0.188 & 0.381 & 0.376 \\
\hline 7 & PX223 & 95 & 80 & 65 & 0.233 & 0.452 & 0.503 \\
\hline 8 & 6130 & 95 & 80 & 55 & 0.354 & 0.436 & 0.928 \\
\hline 9 & 6130 & 90 & 70 & 45 & 0.357 & 0.474 & 1.064 \\
\hline 10 & PX223 & 100 & 80 & 45 & 0.082 & 0.324 & 0.319 \\
\hline 11 & 6130 & 100 & 90 & 45 & 0.287 & 0.402 & 0.772 \\
\hline 12 & PX223 & 95 & 70 & 55 & 0.132 & 0.426 & 0.355 \\
\hline 13 & 6130 & 95 & 70 & 45 & 0.247 & 0.385 & 0.960 \\
\hline 14 & 6130 & 90 & 90 & 65 & 0.581 & 0.590 & 1.640 \\
\hline 15 & 6130 & 100 & 80 & 65 & 0.406 & 0.493 & 0.649 \\
\hline 16 & PX223 & 90 & 90 & 55 & 0.185 & 0.383 & 0.667 \\
\hline 17 & 6130 & 100 & 70 & 55 & 0.387 & 0.486 & 0.457 \\
\hline 18 & PX223 & 90 & 80 & 45 & 0.083 & 0.341 & 0.574 \\
\hline
\end{tabular}

Table $7 \mathrm{~S} / \mathrm{N}$ ratio for the three responses

\begin{tabular}{lrlr}
\hline S. No & $\begin{array}{l}\text { S/N ratio for linear } \\
\text { deviation }(\mathrm{dB})\end{array}$ & $\begin{array}{l}\text { S/N ratio for radial } \\
\text { deviation }(\mathrm{dB})\end{array}$ & $\begin{array}{l}S / N \text { ratio for surface } \\
\text { roughness }(\mathrm{dB})\end{array}$ \\
\hline 1 & 13.00 & 7.70 & 5.24 \\
2 & 6.36 & 6.30 & -0.58 \\
3 & 6.84 & 5.55 & -1.68 \\
4 & 20.82 & 8.29 & 6.90 \\
5 & 14.15 & 8.95 & 6.54 \\
6 & 14.52 & 8.38 & 8.50 \\
7 & 12.65 & 6.90 & 5.97 \\
8 & 9.02 & 7.21 & 0.65 \\
9 & 8.95 & 6.48 & -0.54 \\
10 & 21.72 & 9.79 & 9.92 \\
11 & 10.84 & 7.92 & 2.25 \\
12 & 17.59 & 7.41 & 9.00 \\
13 & 12.15 & 8.29 & 0.35 \\
14 & 4.72 & 4.58 & -4.30 \\
15 & 7.83 & 6.14 & 3.76 \\
16 & 14.66 & 8.34 & 3.52 \\
17 & 8.25 & 6.27 & 6.80 \\
18 & 21.62 & 9.34 & 4.82 \\
\hline
\end{tabular}

compared to 6130 material. Hardener percentage and curing temperature have very little effect as their percentage contribution in LD is very less as seen from the ANOVA table. Curing time affects the LD significantly as seen from its high $F$ value in the ANOVA table. LD increases with increase in curing time and minimum LD is observed when time is $45 \mathrm{~min}$. This may be due to the fact that by increasing the time of keeping, the mould at a specified 
Table 8 ANOVA table for linear deviation (LD)
Table 9 ANOVA table for radial deviation $(\mathrm{RD})$

Table 10 ANOVA table for surface roughness $(\mathrm{SR})$

\begin{tabular}{lcrrrll}
\hline Source & DOF & \multicolumn{1}{c}{ Adj SS } & Adj MS & $F$ value & $P$ value & \% Contribution \\
\hline$A$ & 1 & 319.055 & 319.055 & 144.05 & 0.000 & 67.46 \\
$B$ & 2 & 7.561 & 3.780 & 1.71 & 0.241 & 1.60 \\
$C$ & 2 & 5.672 & 2.836 & 1.28 & 0.329 & 1.20 \\
$D$ & 2 & 119.824 & 59.912 & 27.05 & 0.000 & 25.34 \\
$A \times B$ & 2 & 3.074 & 1.537 & 0.69 & 0.527 & 0.65 \\
Error & 8 & 17.719 & 2.215 & & & 3.75 \\
Total & 17 & 472.904 & & & & 100 \\
\hline
\end{tabular}

\begin{tabular}{lcrrrll}
\hline Source & DOF & \multicolumn{1}{c}{ Adj SS } & Adj MS & $F$ value & $P$ value & \% Contribution \\
\hline$A$ & 1 & 14.8610 & 14.8610 & 314.81 & 0.000 & 46.15 \\
$B$ & 2 & 2.4821 & 1.2411 & 26.29 & 0.000 & 7.71 \\
$C$ & 2 & 0.0273 & 0.0137 & 0.29 & 0.756 & 0.08 \\
$D$ & 2 & 8.7108 & 4.3554 & 92.26 & 0.000 & 27.05 \\
A $\times$ B & 2 & 5.7455 & 2.8728 & 60.86 & 0.000 & 17.84 \\
Error & 8 & 0.3777 & 0.0472 & & & 1.17 \\
Total & 17 & 32.2044 & & & & 100 \\
\hline
\end{tabular}

\begin{tabular}{lcrrrrl}
\hline Source & DOF & Adj SS & Adj MS & $F$ value & $P$ value & \% Contribution \\
\hline$A$ & 1 & 160.117 & 160.117 & 152.05 & 0.000 & 57.55 \\
$B$ & 2 & 78.532 & 39.266 & 37.29 & 0.000 & 28.22 \\
$C$ & 2 & 19.096 & 9.548 & 9.07 & 0.009 & 6.87 \\
$D$ & 2 & 3.692 & 1.846 & 1.75 & 0.234 & 1.32 \\
$A \times B$ & 2 & 8.386 & 4.193 & 3.98 & 0.063 & 3.01 \\
Error & 8 & 8.424 & 1.053 & & & 3.03 \\
Total & 17 & 278.247 & & & & 100 \\
\hline
\end{tabular}

Fig. 4 Main effect plot of $S /$ $N$ ratios for $\mathrm{LD}$

\section{Main Effects Plot for SN ratios}

Data Means

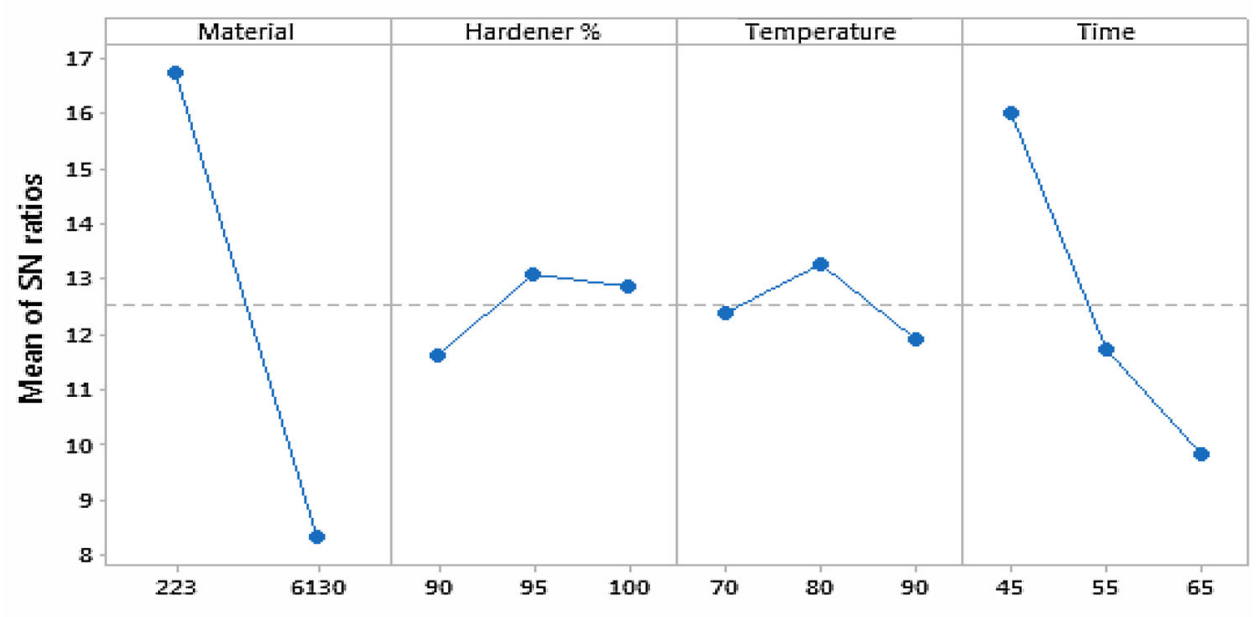

Signal-to-noise: Smaller is better

temperature after VC shrinks the material more and hence causes more deviation. Higher the $S / N$ ratio, more favourable is the effect of input variable on the response.
Therefore, it has been observed that optimum parameter setting that minimizes the LD is $A_{2}, B_{2}, C_{2}$, and $D_{1}$ (see Fig. 4). 
Figure 5 shows the main effect plot for mean $S / N$ ratio of various factors for the average linear deviation (RD). Similar to LD, RD is also less for PX223 PU material as compared to 6130 material. In addition, RD decreases with increase in hardener percentage and in this case, minimum $\mathrm{RD}$ is found when hardener percentage is 100. Curing temperature has very little effect on the RD. Curing time affects the RD significantly as seen from its high $F$ value in the ANOVA table. RD increases with increase in curing time and minimum RD is found when time is $45 \mathrm{~min}$. The reason for the increase in $\mathrm{RD}$ with curing time is similar as in case of LD. From Fig. 5, it has been observed that optimum parameter setting that minimizes the RD is $A_{2}$, $B_{3}, C_{2}$, and $D_{1}$.

Figure 6 shows the main effect plot for mean $S / N$ ratio for the average surface roughness (SR). Similar to LD and $\mathrm{RD}, \mathrm{SR}$ is also less for PX223 PU as compared to $6130 \mathrm{PU}$. SR decreases with increase in hardener percentage and minimum SR is obtained when hardener percentage is 100 . Curing temperature affects the SR significantly. SR increases with increase in curing time and minimum SR is obtained when temperature is $70^{\circ}$. Curing time has very little effect on the SR. From Fig. 6, it has been observed that optimum parameter setting that minimizes the $\mathrm{SR}$ is $A_{2}, B_{3}, C_{1}$ and $D_{2}$.

\section{Calculation of tolerance grades}

To find the tolerance grades of the fabricated components, first the measured dimensions have been used to evaluate the tolerance unit ' $n$ ' that drives from the fundamental tolerance ' $i$ ', as defined in ISO standard UNI EN 20286-I (1995) and DIN 16901 for plastic materials. In addition, the fundamental tolerance ' $i$ ' is not evaluated separately for each nominal size, but for a range of nominal sizes. The fundamental tolerance ' $i$ ' and tolerance unit ' $n$ ' are calculated by the following equations [27, 28]:

$i=0.45 \sqrt[3]{D}+0.001 D$

$n=1000\left(\frac{\left|D_{\mathrm{N}}-D_{\mathrm{M}}\right|}{i}\right)$,

where ' $D$ ' is the geometric mean of range of nominal size, $D_{\mathrm{N}}$ is the nominal dimension, $D_{\mathrm{M}}$ is the measured dimension, and ' $i$ ' is the fundamental tolerance in $\mu \mathrm{m}$.

In this research work, the linear dimension $(25.042 \mathrm{~mm})$ and radial dimension $(12.356 \mathrm{~mm}$ ) of the master prototype fabricated by combined process of FDM and CVS have been taken as nominal dimensions. The standard basic step for linear dimension is $18-30 \mathrm{~mm}$ and that for radial dimension is $10-18 \mathrm{~mm}$. In experiment 1 , the value of ' $n$ ' for the selected linear and radial dimension is calculated as follows:

$$
\begin{aligned}
& D=(18 \times 30)^{1 / 2}=23.238 \mathrm{~mm} \\
& i=0.45(23.238)^{1 / 3}+0.001(23.238)=1.3073 \mu \mathrm{m} \\
& n=1000(25.042-24.818) / 1.3073=171.35 \\
& D=(10 \times 18)^{1 / 2}=13.416 \mathrm{~mm} \\
& i=0.45(13.416)^{1 / 3}+0.001(13.416)=1.0827 \mu \mathrm{m} \\
& n=1000(12.356-11.944) / 1.0827=380.53
\end{aligned}
$$

Similarly, the values of ' $n$ ' for all the experimental runs were calculated and the corresponding IT grades have been obtained, as shown in Table 11. It has been observed that in all the experiments, the measured dimensions are less than the nominal dimensions. It was due to the shrinkage that occurs during solidification of the replicas as the plastic changes state from liquid to solid. This shrinkage can be easily compensated by providing shrinkage
Fig. 5 Main effect plot of $S /$ $N$ ratios for RD

\section{Main Effects Plot for SN ratios} Data Means

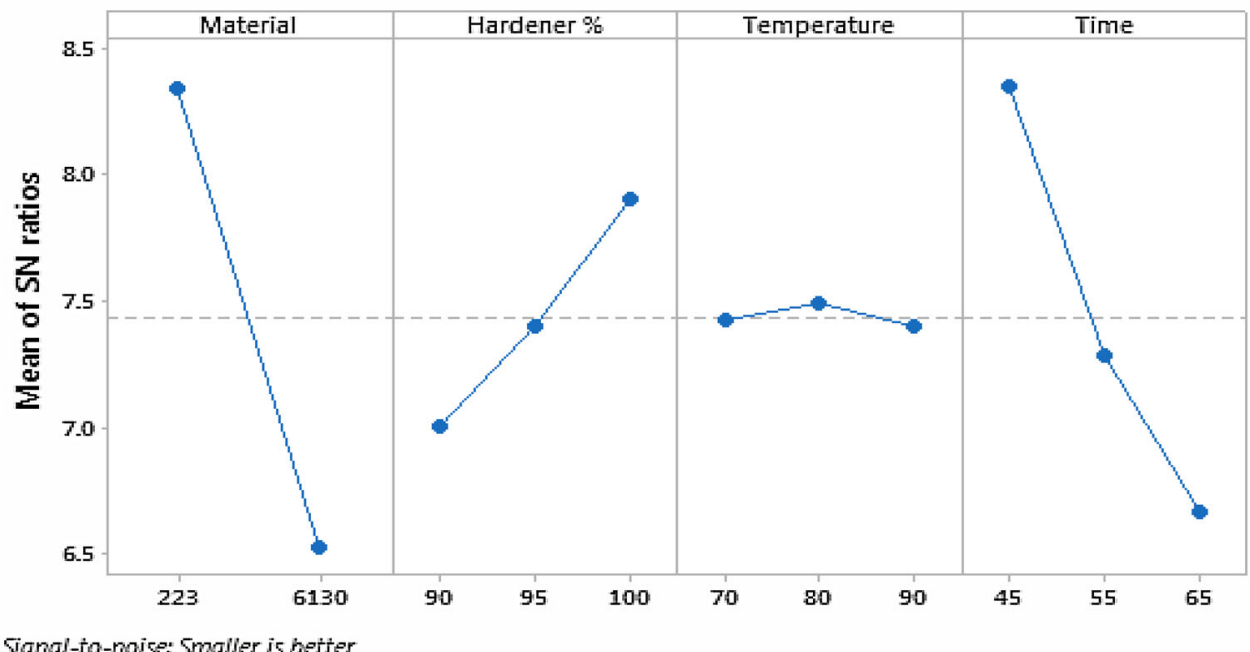


Fig. 6 Main effect plot of $S /$ $N$ ratios for SR
Main Effects Plot for SN ratios

Data Means.

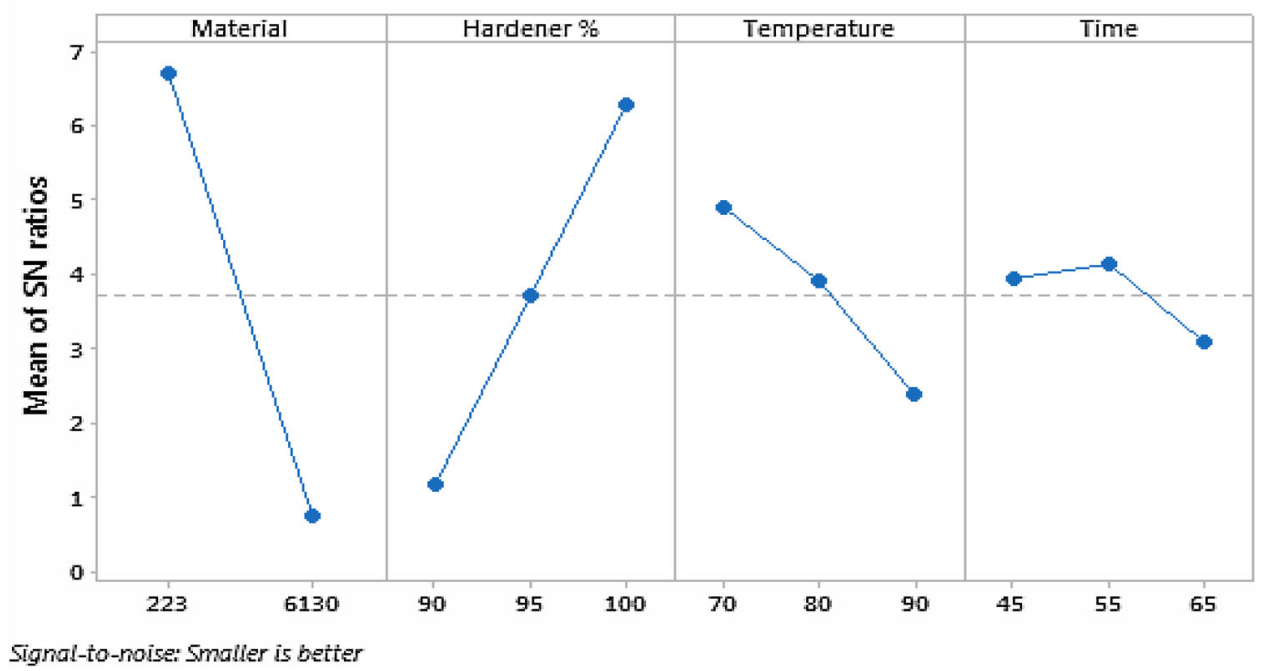

allowance to the master pattern. The results indicates that the IT grades of the fabricated replicas are consistent with the permissible range of tolerance grades as per ISO standard UNI EN 20286-I (1995) and DIN 16901 for plastic materials.

\section{Optimization and confirmation experiments}

From Tables 8, 9, and 10, it has been observed that significant factors and their percentage contribution for the three responses are different. Similarly, optimum parameter levels for the three responses are also different. Therefore, instead of optimizing the individual response in an arbitrarily manner, it has been desirable to obtain the parameter settings that simultaneously give the better results. To achieve the above objective, the response optimization module of 'Minitab 17' software has been used. The constraints set and the optimum values along with the desirability suggested by the software have been shown in Table 12.

The calculated $\mathrm{LD}, \mathrm{RD}$, and SR corresponding to $\mathrm{S} /$ $N$ ratio of 20.51, 10.04, and 9.70 are $0.094 \mathrm{~mm}, 0.315 \mathrm{~mm}$, and $0.327 \mu \mathrm{m}$, respectively. To check the validity of the

Table 11 Calculations of IT grades

\begin{tabular}{|c|c|c|c|c|c|c|}
\hline Exp No. & Linear dimension $(\mathrm{mm})$ & Tolerance value ' $n$ ' & IT grade & Radial dimension (mm) & Tolerance value ' $n$ ' & IT grade \\
\hline 1 & 24.818 & 171.35 & IT12 & 11.944 & 380.53 & IT14 \\
\hline 2 & 24.561 & 367.93 & IT14 & 11.872 & 447.03 & IT15 \\
\hline 3 & 24.587 & 348.05 & IT14 & 11.828 & 487.67 & IT15 \\
\hline 4 & 24.951 & 69.61 & IT10 & 11.971 & 355.59 & IT14 \\
\hline 5 & 24.846 & 149.93 & IT12 & 11.999 & 329.73 & IT14 \\
\hline 6 & 24.854 & 143.81 & IT12 & 11.975 & 351.90 & IT14 \\
\hline 7 & 24.809 & 178.23 & IT12 & 11.904 & 417.47 & IT14 \\
\hline 8 & 24.688 & 270.79 & IT13 & 11.920 & 402.70 & IT14 \\
\hline 9 & 24.685 & 273.08 & IT13 & 11.882 & 437.79 & IT15 \\
\hline 10 & 24.960 & 62.72 & IT10 & 12.032 & 299.25 & IT14 \\
\hline 11 & 24.755 & 219.54 & IT13 & 11.954 & 371.29 & IT14 \\
\hline 12 & 24.910 & 100.97 & IT11 & 11.930 & 393.46 & IT14 \\
\hline 13 & 24.795 & 188.94 & IT12 & 11.971 & 355.59 & IT14 \\
\hline 14 & 24.461 & 444.43 & IT14 & 11.766 & 544.93 & IT15 \\
\hline 15 & 24.636 & 310.56 & IT13 & 11.863 & 455.34 & IT15 \\
\hline 16 & 24.857 & 141.51 & IT12 & 11.973 & 353.75 & IT14 \\
\hline 17 & 24.655 & 296.03 & IT13 & 11.870 & 448.88 & IT15 \\
\hline 18 & 24.959 & 63.49 & IT10 & 12.015 & 314.95 & IT14 \\
\hline
\end{tabular}


Table 12 Constraints and optimum values suggested by the software

Fig. 7 a, b SR profile of samples fabricated at optimum parameter setting

\begin{tabular}{|c|c|c|c|c|c|c|c|}
\hline \multicolumn{2}{|l|}{ Name } & \multicolumn{2}{|l|}{ Goal } & Lower limit & Upper limit & Weight & Importance \\
\hline \multicolumn{2}{|c|}{ PU material } & \multicolumn{2}{|c|}{ Constraint to region } & 6130 & PX223 & 1 & 1 \\
\hline \multicolumn{2}{|c|}{ Hardener \% } & \multicolumn{2}{|c|}{ Constraint to region } & 90 & 100 & 1 & 1 \\
\hline \multicolumn{2}{|c|}{ Curing temperature } & \multicolumn{2}{|c|}{ Constraint to region } & 70 & 90 & 1 & 1 \\
\hline \multicolumn{2}{|c|}{ Curing time } & \multicolumn{2}{|c|}{ Constraint to region } & 45 & 65 & 1 & 1 \\
\hline \multicolumn{2}{|c|}{$S / N$ ratio (LD) } & \multicolumn{2}{|l|}{ Maximize } & 4.73 & 21.94 & 1 & 1 \\
\hline \multicolumn{2}{|c|}{$S / N$ ratio $(\mathrm{RD})$} & \multicolumn{2}{|l|}{ Maximize } & 4.58 & 9.90 & 1 & 1 \\
\hline \multicolumn{2}{|c|}{$S / N$ ratio $(\mathrm{SR})$} & \multicolumn{2}{|l|}{ Maximize } & -4.30 & 9.92 & 1 & 1 \\
\hline $\begin{array}{l}\mathrm{PU} \\
\text { material }\end{array}$ & $\begin{array}{l}\text { Hardener } \\
\%\end{array}$ & $\begin{array}{l}\text { Curing } \\
\text { temperature }\end{array}$ & $\begin{array}{l}\text { Curing } \\
\text { time }\end{array}$ & $\begin{array}{l}S / N \text { ratio } \\
\text { (LD) }\end{array}$ & $\begin{array}{l}S / N \text { ratio } \\
(\mathrm{RD})\end{array}$ & $\begin{array}{l}S / N \text { ratio } \\
(\mathrm{SR})\end{array}$ & Desirability \\
\hline \multicolumn{8}{|c|}{ Optimum values } \\
\hline PX223 & 100 & 70 & 45 & 20.51 & 10.04 & 9.70 & 0.966 \\
\hline
\end{tabular}

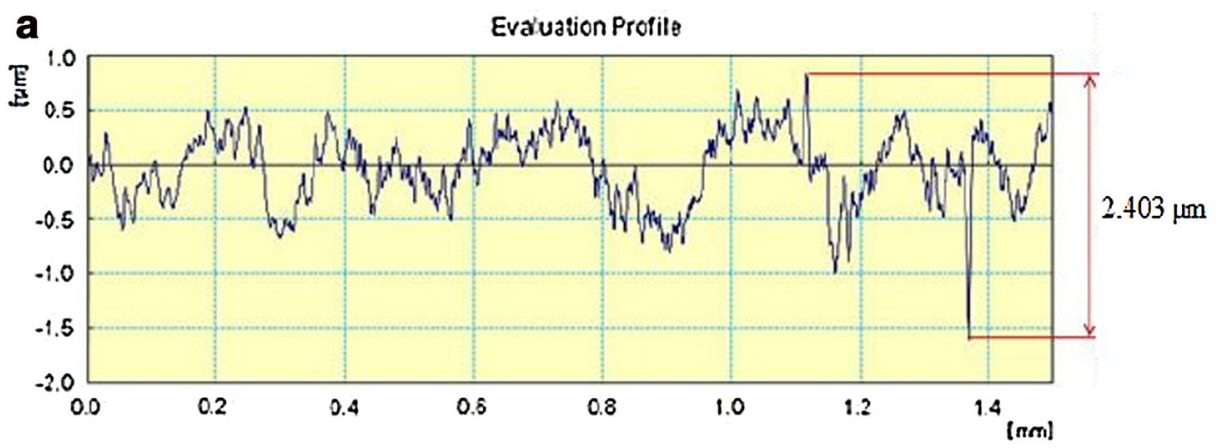

Average Roughness, $\mathrm{Ra}=0.338 \mu \mathrm{m}$

Peak to valley height $=2.403 \mu \mathrm{m}$

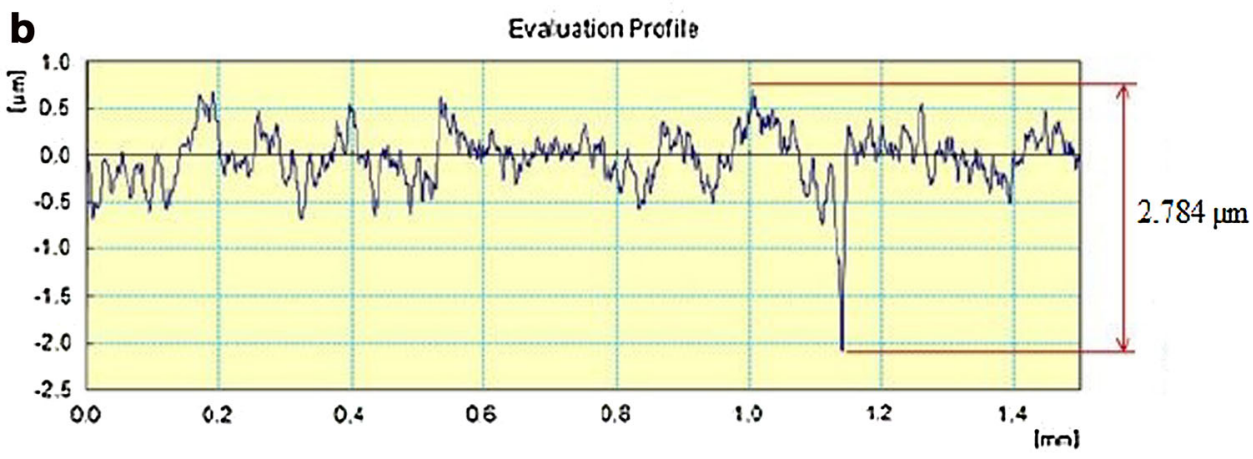

Surface Roughness, $R a=0.342 \mu \mathrm{m}$

Peak to valley height $=2.784 \mu \mathrm{m}$ results suggested by the software, two confirmation tests were performed at optimum parameter values as given in Table 11. The LD, RD, and SR for the two confirmation tests were found to be $(0.091,0.096 \mathrm{~mm}),(0.309$, $0.318 \mathrm{~mm})$, and $(0.338,0.342 \mu \mathrm{m})$, respectively. This confirms the excellent reproducibility of the experimental conclusions. The surface roughness $\left(R_{\mathrm{a}}\right)$ profile of the two samples fabricated at optimal parameter settings has been shown in Fig. 7a and b, respectively. The peak-to-valley height of the samples was found to be 2.403 and $2.784 \mu \mathrm{m}$, respectively, whereas the $R_{\mathrm{a}}$ values of the samples were 0.338 and $0.342 \mu \mathrm{m}$, respectively. 
Table 13 Observations of selected dimension at optimum parameter setting

\begin{tabular}{lll}
\hline S. No & Observations & IT grade \\
\hline 1 & 24.952 & IT10 \\
2 & 24.945 & IT10 \\
3 & 24.949 & IT10 \\
4 & 24.948 & IT10 \\
5 & 24.946 & IT10 \\
6 & 24.950 & IT10 \\
7 & 24.956 & IT10 \\
8 & 24.953 & IT10 \\
9 & 24.944 & IT10 \\
10 & 24.952 & IT10 \\
11 & 24.949 & IT10 \\
12 & 24.951 & IT10 \\
13 & 24.954 & IT10 \\
14 & 24.942 & IT10 \\
15 & 24.946 & IT10 \\
\hline
\end{tabular}

\section{Calculation of process capability}

Furthermore, to check whether the process is statistically controlled or not, 15 samples were fabricated at optimum parameter settings. Linear dimension of the fabricated components measured with CMM along with calculated IT grades were shown in Table 13. After that, the $C_{\mathrm{p}}$ and $C_{\mathrm{pk}}$ values of the process and histogram of observed values have been obtained by 'Process Capability Wizard 2016' software, as shown in Fig. 8. The prerequisite for computing $C_{\mathrm{p}}$ and $C_{\mathrm{pk}}$ is that the process is required to be under statistical control and that the data are normally distributed [29, 30]. Since the value of both $C_{\mathrm{p}}$ and $C_{\mathrm{pk}}$ is found to be greater than 1.33 , it indicates that the process is statistically controlled. In this work, corresponding to $C_{\mathrm{pk}}$ value of 1.39 for the selected dimension, area under the normal curve is 0.99994871 and non-confirming parts per million are 51.29. It means that the process will produce conforming products as long as it remains in statistically controlled. Furthermore, normal probability plot (see Fig. 9) shows that the data are normally distributed. The observed values
Fig. 8 Histogram of observed data along with $C_{\mathrm{p}}$ and $C_{\mathrm{pk}}$ values of the process

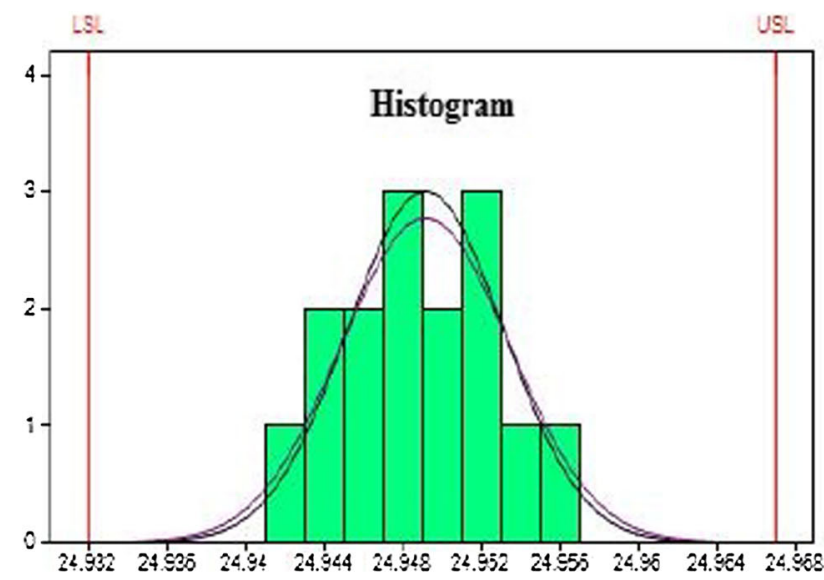

$\mathrm{LSL}=24.932$

USL $=24.966$

Readings $=15$

Mean $=24.949$

Median $=24.950$

Std. Deviation (overall) $=0.003979$

Std. Deviation (within) $=0.004051$

$\mathrm{Cp}=1.40$

$\mathrm{Cpk}=1.39$
Fig. 9 Normal distribution curve for observed values

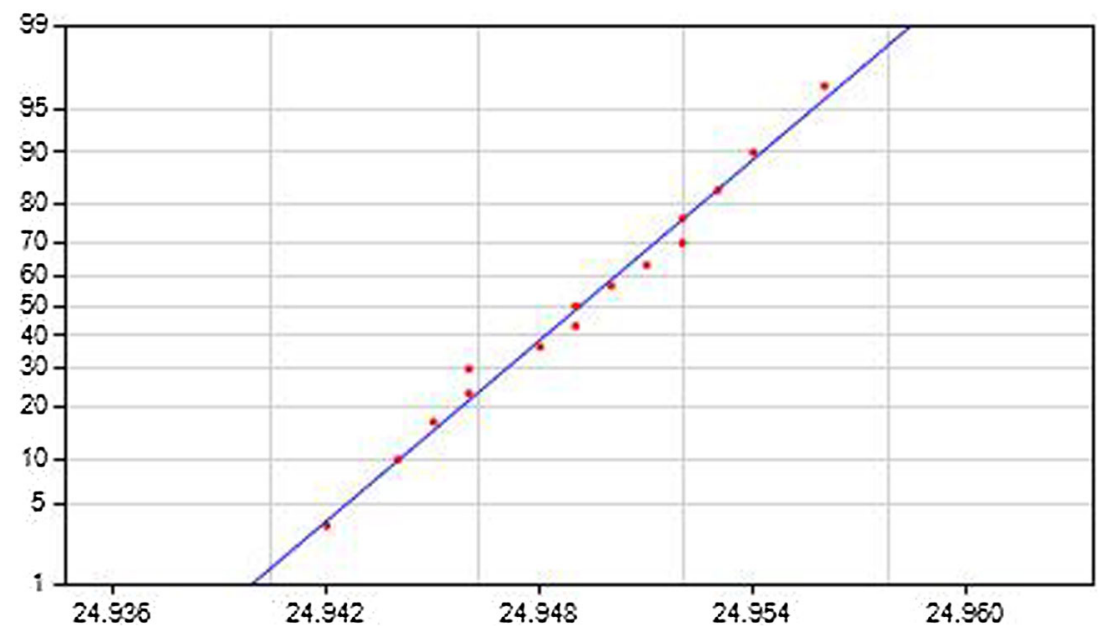


are plotted on the $X$-axis against a theoretical normal distribution ( $z$-scores) on the $Y$-axis [30]. A regression line is drawn from these $X Y$ pair which shows points closer to the regression line and thus indicating a good fit.

\section{Conclusions}

In this research work, the effect of selected input parameters of $\mathrm{VC}$ process on the dimensional accuracy (linear as well as radial) and surface finish of PU replicas has been investigated. Shrinkage has been observed in both the selected dimensions after the VC process. The maximum linear and radial shrinkages have been observed for 6130 PU material and its values are 2.31 and $4.77 \%$, respectively. PU material affects all the responses significantly. Curing time is the next factor that affects the LD and RD. Small value of $\mathrm{LD}$ and RD has been observed with low curing time. Although, hardener percentage affects the RD significantly, but its percentage contribution is low. Both the PU material shows good surface finish after VC as required by the industry. Hardener percentage is the main factor affecting SR after the PU material. The parameter settings that give optimum results when all the responses considered simultaneously are PX223 PU material, 100\% hardener, and curing temperature of $70^{\circ}$ with curing time of $45 \mathrm{~min}$. The tolerance grades for the selected dimensions of the fabricated replicas were found to be acceptable as per the ISO standard UNI EN 20286-I (1995) and DIN16901 for plastic materials. In addition, $C_{\mathrm{pk}}$ value greater than 1.3 indicates that the proposed process is highly capable. The surface finish and dimensional accuracy of prototypes are as accurate as in traditional moulding, and hence, they can be used as end-products or plastic patterns for investment casting.

Acknowledgements The authors are thankful to IKG Punjab Technical University, Manufacturing Research Lab (GNDEC, Ludhiana), and CTR, Ludhiana for providing research facilities. The authors are also thankful to Mr. Puran Singh (lab technician) for providing their technical support.

\section{References}

1. Gill SS, Kaplas M (2009) Comparative study of 3D printing technologies for rapid casting of aluminum alloy. Mater Manuf Processes 24:1405-1411

2. Singh R, Verma M (2008) Investigations for reducing wall thickness of aluminum shell casting using three dimensional printing. J Achiev Mater Manuf Eng 31:65-69

3. Singh R (2010) Three-dimensional printing for casting applications: a state of art review and future perspectives. Adv Mater Res 42:83-86

4. Rosochowski A, Matuszak A (2000) Rapid tooling - the state of art. J Mater Process Technol 106:191-198
5. Ma S, Gibson I, Balaji G, Hu QJ (2007) Development of epoxy matrix composites for rapid tooling applications. J Mater Process Technol 192(193):75-82

6. Boparai K, Singh R, Singh H (2016) Development of rapid tooling using fused deposition modeling: a review. Rapid Prototyp J. doi:10.1108/RPJ-04-2014-0048

7. Kruth PJ (1991) Material increases manufacturing by rapid prototyping techniques. Ann CIRP 40(2):603-614

8. Karunakaran KP, Bernard A, Suryakumar S, Dembinski L, Taillandier G (2012) Rapid manufacturing of metallic objects. Rapid Prototyp J 18(4):264-280

9. Chhabra M, Singh R (2011) Rapid casting solutions: a review. Rapid Prototyp J 17(5):328-350

10. Smith BJ, St Jean P, Duquette ML (1996) A comparison of rapid prototype techniques for investment casting Be-Al. In: Proceedings of Rapid Prototyping and Manufacturing Conference, Dearbon, MI, 23-25, pp 1-11

11. Chung S, Park S, Lee I, Jeong H, Cho D (2005) Replication techniques for a metal micro-component having real 3D shape by microcasting process. MicrosysTechnol 11:424-428

12. Tang Y Tan, Fuh WK, Loh JYH, Wong HT, Thian YS, Lu SCH (2007) Micro mould fabrication for micro-gear via vacuum casting. J Mater Process Technol 192-193:334-339

13. Cheah CM, Chua CK, Lee CW, Feng C, Totong K (2005) Rapid prototyping and tooling techniques: a review of applications for rapid investment casting. Int $\mathrm{J}$ Adv Manuf Technol 25(3-4):308-320

14. Dinesh P, Ravi R (2007) Rapid tooling route selection and evaluation for sand and investment casting. Virtual Phys Prototyp 2:197-207

15. Rahmati S, Akbari J, Barati E (2007) Dimensional accuracy analysis of wax patterns created by RTV silicon rubber molding using Taguchi approach. Rapid Prototyp J 13(2):115-122

16. Yarlagadda P, Hock TS (2003) Statistical analysis on accuracy of wax patterns used in investment casting. J Mater Technol 138:75-81

17. Zamani J, Hemati MH, Morsaluie R (2014) An experimental comparison on dimensional accuracy of wax patterns of gas turbine blades produced by rapid tooling. Arab J SciEng 39:7289-7297

18. Thian SCH, Tang Y, Tan WK, Fuh JYH, Wong YS, Loh HT, Lu L (2008) The manufacture of micromould and micropartsby vacuum casting. Int J Adv Manuf Technol 38:944-948

19. Sharma V, Singh R (2011) Investigations for modeling the silicon moulding process for plastic components. Int J Mater Sci Eng $2: 1-2$

20. Singh R, Singh B (2010) Process capability of rapid manufacturing for plastic components. LAP Lambert Accademic Publication, Germany, p 76. ISBN 978-3-8433-8735-4

21. Kai CC, Howe CT, Hoe EK (1998) Integrating rapid prototyping and tooling with vacuum casting for connectors. Int J Adv Manuf Technol 14:617-623

22. Kumar P, Singh R, Ahuja IPS (2015) Investigations on dimensional accuracy of the components prepared by hybrid investment casting. J Manuf Processes. doi:10.1016/j.jmapro.2015.07.008

23. Garg A, Bhattacharya A, Batish A (2015) On surface finish and dimensional accuracy of FDM parts after cold vapor treatment. Mater Manuf Processes. doi:10.1080/10426914.2015.1070425

24. Singh J, Singh R, Singh H (2017) Investigations for improving the surface finish of FDM based ABS replicas by chemical vapor smoothing process: a case study. Assem Autom 37(1):13-21

25. Singh J, Singh R, Singh H (2016) Repeatability of linear and radial dimension of ABS replicas fabricated by fused deposition modelling and chemical vapor smoothing process: a case study. Measurement 94:5-11 
26. Singh JS, Singh R, Boparai KS (2016) Parametric optimization of fused deposition modeling and vapour smoothing processes for surface finishing of biomedical implant replicas. Measurement 94:602-613

27. Singh JP, Singh R (2009) Investigations for statistically controlled rapid casting solution of lead alloys using three dimensional printing. J Mech Eng Sci 223:2125-2134

28. Bassoli E, Gatto A, Luliano L, Violentte MG (2007) 3D printing technique applied to rapid casting. Rapid Prototyp J 13:148-155
29. Singh R (2012) Effect of work piece volume on statistically controlled rapid casting solution of aluminum alloys using three dimensional printing. Mater Manuf Processes 27(4):377-382

30. Singh R (2014) Process capability analysis of fused deposition modelling for plastic components. Rapid Prototyp J 20(1):69-76 